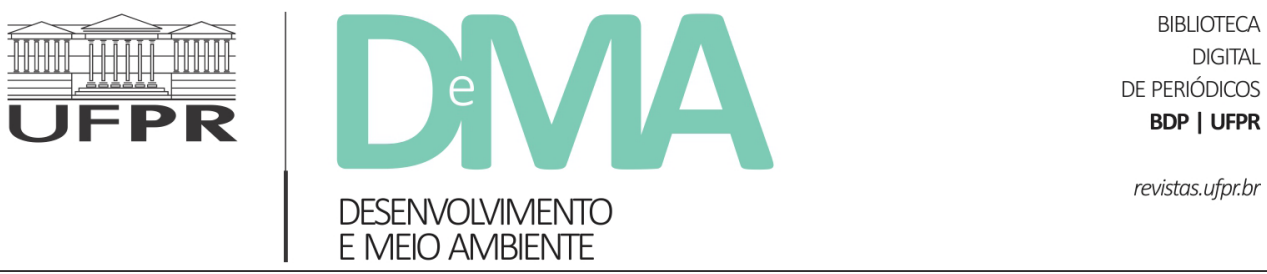

\title{
Educação ambiental escolar a partir da agroecologia e da permacultura: a experiência do projeto Escola Permacultural
}

\section{School environmental education through agroecology and permaculture: the experience of the Permacultural School Project}

\author{
Paolo de Castro MARTINS ${ }^{1 *}$, Diogo Majerowicz MANESCHY², Juliana Sarcinelli MENEZES ${ }^{1,2}$, Roberta \\ Donati Pignatari Vilela GUERRA ${ }^{1,2}$, Celso Sánchez PEREIRA ${ }^{1}$ \\ ${ }^{1}$ Universidade Federal do Estado do Rio de Janeiro (UNIRIO), Rio de Janeiro, Brasil. \\ ${ }^{2}$ Instituto Permacultura Lab, Rio de Janeiro, RJ, Brasil. \\ *E-mail de contato: massoni.paolo@gmail.com
}

Artigo recebido em 30 de março de 2020, versão final aceita em 25 de fevereiro de 2021, publicado em 7 de outubro de 2021

RESUMO: Este artigo tem como objetivo trazer reflexões sobre interlocuções existentes entre a agroecologia e a permacultura com a educação ambiental, mais especificamente com a educação ambiental escolar. Temos a intenção de trazer uma apresentação sobre como essas áreas temáticas podem atuar como elementos-chave para facilitar um processo pedagógico comprometido com o desvelamento e a busca de soluções para diferentes dimensões da crise socioambiental contemporânea. Nesse contexto, serão apresentados resultados de uma experiência de educação ambiental escolar que tem como base a agroecologia e a permacultura enquanto disciplinas escolares, oferecidas para o ensino médio de uma escola estadual da periferia da cidade do Rio de Janeiro.

Palavras-chave: educação ambiental crítica; educação popular; agroecologia; permacultura.

ABSTRACT: This article aims to reflect on the interlocutions between agroecology and permaculture with environmental education, more specifically with school environmental education. We intend to bring a presentation on how these thematic areas can act as key elements to facilitate a pedagogical process committed to the unveiling and the search for solutions to different dimensions of the contemporary socio-environmental crisis. In this context, the results of a school environmental education experience based on agroecology and permaculture as school subjects will be presented, offered for high school in a state school on the outskirts of the city of Rio de Janeiro.

Keywords: critical environmental education; popular education; agroecology; permaculture.

Desenvolv. e Meio Ambiente usa uma Licença Creative Commons - Atribuição-NãoComercial-SemDerivações 4.0 Internacional 


\section{Introdução}

A forma desarmônica de relação entre as sociedades contemporâneas e o ambiente tem produzido inúmeros impactos socioambientais. Em função da magnitude e da abrangência desses impactos por todo o planeta, torna-se inegável a existência de uma crise socioambiental como nunca houve na história da humanidade (Guimarães, 2016).

É fundamental que se tenha clara a noção de que as graves condições ambientais e sociais existentes no mundo hoje não são produto do acaso. Tal realidade é fruto de um processo histórico de construção da sociedade, dirigido por instituições globais e governos, pautado no desenvolvimento econômico ilimitado e na exploração dos recursos naturais e da mão de obra humana (Layrargues, 2014).

A tomada de consciência da gravidade da crise socioambiental levou ao surgimento do movimento ambientalista em diversos países a partir da década de 1970 (Trein, 2012). No Brasil, o movimento ambientalista ganhou notoriedade no início dos anos 80, com o processo de redemocratização do país (Guimarães, 2016). Além do retorno de exilados políticos que se envolveram com o movimento ambientalista no exterior, a luta dos seringueiros em conjunto com indígenas e agricultores tradicionais no Norte do país, com a liderança de Chico Mendes, é um marco na história do ambientalismo brasileiro (Almeida, 2004).

Já na década de 1990, impulsionada pela conferência da ONU Rio 92, há uma maior união entre as pautas ambientais com as consequências sociais e políticas do modelo de desenvolvimento, bem como a inclusão da dimensão ambiental nas pautas de diversos movimentos sociais, como o MAB - Movimento dos Atingidos por Barragens - e o MST - Movimento do Trabalhadores Rurais Sem Terra (Acselrad, 2010).

Junto à denúncia dos impactos socioambientais oriundos do modelo de sociedade baseado no capitalismo moderno-industrial, que levou também à industrialização da agricultura, com a chamada Revolução Verde, surgem, a partir da década de 1970, buscas de alternativas a esse modelo (Holt-Gimenez \& Altieri, 2013). Nesse contexto, tem origem a agroecologia e a permacultura, que são temas que têm ganhado força em diferentes setores da sociedade.

A agroecologia pode ser entendida como uma ciência que fornece as bases ecológicas, metodológicas e técnicas para o desenvolvimento de uma agricultura sustentável (Altieri, 2012). Porém, ao mesmo tempo em que apresenta uma visão ecológica e técnica do agroecossistema, contempla também as condições sociais e culturais dos agricultores (Leff, 2002) e, dessa maneira, defende a necessidade da produção de conhecimento de maneira sistêmica (Sevilla Guzmán, 2001). Desse modo, a agroecologia tem como característica o estudo integrado dos processos ambientais e sociais, compreendendo-os como sistemas socioambientais complexos (Floriani $\&$ Floriani, 2010). Com isso, promove um resgate de saberes tradicionais e sua hibridização com saberes científicos modernos, em uma mistura que proporciona o fortalecimento ambiental e sociocultural das comunidades e dos agroecossistemas (Leff, 2002).

Sua origem ocorre a partir das ideias de pesquisadores de várias partes do mundo que contestaram o modelo de produção agrícola baseado no uso de agrotóxicos e de fertilizantes sintéticos, nas monoculturas e no uso de grandes máquinas, e 
propuseram alternativas baseadas em perspectivas ecológicas da agricultura. Entre eles destacam-se Ana Maria Primavesi e Adilson Paschoal, no Brasil, além de pesquisadores de outros países como Rachel Carson, Masanobu Fukuoka, Albert Howard e Francis Chaboussou (Monteiro \& Londres, 2017).

A partir da década de 1980 ocorreu o surgimento de movimentos agroecológicos, num processo em que movimentos sociais - camponeses e indígenas - incorporaram a agroecologia como um de seus princípios. Ao apresentar reflexões e alternativas sobre múltiplas questões - sociais, políticas, ambientais, econômicas, de gênero e etnia - a agroecologia se insere de maneira significativa nesses movimentos (Prates Júnior et al., 2016).

A permacultura consiste em um método de design de paisagens, que busca a maior eficiência energética possível e o menor impacto ambiental. Além disso, pode ser compreendida também como uma proposta filosófica, ética e técnica de transformação da sociedade. A partir de uma visão sistêmica, baseia-se na noção de que o ser humano faz parte de um todo maior, que não pode ser desassociado dos ecossistemas e dos outros seres vivos. Esse conceito foi criado na década de 1970 pelos australianos Bill Molison e David Holmgreen, tendo como base inicial a busca de caminhos para o desenvolvimento de uma agricultura mais equilibrada sob o ponto de vista socioambiental. Posteriormente, o termo foi ampliado para a noção de "cultura permanente" e, além da agricultura, passou a contemplar visões relacionadas à energia renovável, arquitetura, formas de organização comunitária, relações interpessoais e relações dos seres humanos com outras espécies (Nanni et al., 2018).

Este artigo parte desse cenário para pensar em como a agroecologia e a permacultura se enxertam no contexto escolar. Perguntamos como a educação ambiental (EA) em escolas pode se nutrir da agroecologia e da permacultura. Nosso objetivo é buscar as interlocuções existentes entre esses campos para poder colher os frutos dessas conexões. Entendemos que a EA em contexto formal, ou seja, na escola, apresenta possibilidades importantes que incluem o amplo debate sobre como as realidades escolares refletem as diferentes realidades sociais (Martins et al., 2019).

\section{Educação ambiental e os solos férteis do pensamento crítico}

As mudanças climáticas globais, que alguns anos atrás poderiam ser interpretadas como o anúncio de um futuro distópico, tornaram-se uma realidade incontestável e suas consequências já podem ser sentidas no presente (Allen et al., 2018). Como exemplo, têm-se as temperaturas acima de $40^{\circ} \mathrm{C}$ no verão europeu de 2019, o acentuado derretimento das geleiras na Antártida e a seca severa que gerou incêndios sem precedentes na Austrália, nos meses de dezembro de 2019 e janeiro de 2020 (Nolan et al., 2020). Com essas e outras evidências, é consenso para grande parte da sociedade que existe uma grave crise socioambiental, que esta é decorrente de um modelo de desenvolvimento econômico e que a EA é uma importante ação para a busca da superação destes problemas (Guimarães, 2016).

A importância da presença da EA no processo educacional se reflete na existência de políticas públicas como a Política Nacional de Educação Ambiental, lei federal ${ }^{\circ} 9.795$, de 27 de abril de 1999, que considera que: “Art. $2^{\circ}$. A EA é um componente essencial e permanente da educação nacional, de- 
vendo estar presente, de forma articulada, em todos os níveis e modalidades do processo educativo, em caráter formal e não-formal" (Brasil, 1999).

Uma pesquisa desenvolvida pelo Instituto Nacional de Estudos e Pesquisas Educacionais Anísio Teixeira - INEP, em 2004, verificou que 94\% das escolas de ensino fundamental do país declaram que desenvolvem EA no currículo, sob a forma de projetos ou de disciplina específica, o que pode ser considerado como a universalização da EA nas escolas brasileiras (Veiga et al., 2005). Porém, existe uma diversidade de perspectivas da EA, que apresenta significativas diferenças de abordagem, em função das bases epistemológicas, pedagógicas e políticas que a orientam.

Em consequência desse resultado, o governo federal à época, quando ainda se preocupava com a educação brasileira e com questões ambientais, realizou um segundo estudo intitulado "O que fazem as escolas que dizem que fazem educação ambiental" (Trajber \& Mendonça, 2007), onde se avaliou qualitativamente os resultados das ações de EA. O estudo evidenciou que nas ações de EA há pouca apropriação do debate socioambiental, prevalecendo ações muitas vezes desconexas das questões ambientais locais. Tal cenário levou pesquisadores a problematizar os diferentes matizes da EA brasileira.

Nesse sentido, Layrargues \& Lima (2014) identificam três macrotendências da EA. São elas a conservacionista, a pragmática e a crítica. A macrotendência conservacionista possui grande influência da ecologia e se embasa na mudança de comportamento individual e na valorização dos elementos naturais. A pragmática se alinha à visão do desenvolvimento sustentável, sob a ótica neoliberal. Seus princípios estão ligados à preo- cupação com o consumo e produção de resíduos, bem como com a responsabilidade socioambiental e a certificação das empresas (Layrargues \& Lima, 2014). De acordo com os autores, as macrotendências conservacionista e pragmática fazem parte de uma mesma linhagem ideológica e possuem uma importante característica em comum, que consiste no fato de não incluírem as dimensões sociais e políticas à perspectiva ambiental. Dessa maneira, ambas se alinham à perspectiva conservadora da EA (Guimarães, 2004). A macrotendência crítica, por outro lado, tem como base a problematização politizada e contextualizada dos componentes que integram a complexa discussão ambiental (Layrargues \& Lima, 2014).

$\mathrm{Na}$ perspectiva crítica da EA, busca-se a compreensão e atuação sobre as relações de poder que permeiam e estruturam a sociedade (Guimarães, 2016). As questões ambientais necessitam ser abordadas de maneira contextualizada com a realidade de cada comunidade, considerando as complexas relações políticas, econômicas e ideológicas existentes. Sendo assim, não se pode falar em mudanças de comportamentos sem considerar os diferentes contextos de vida dos indivíduos e suas reais possibilidades de existir.

\section{Semeando inéditos viáveis: uma breve descrição do projeto Escola Permacultural}

De acordo com Paulo Freire (2014), as pessoas que reconhecem suas condições de sujeitos históricos oprimidos deparam-se com "situações limites", ou seja, condições que impedem o pleno desenvolvimento de suas vidas. Tais sujeitos, que possuem uma percepção crítica da realidade de 
que fazem parte, são capazes de caminhar rumo à superação dessas condições, indo ao encontro dos "inéditos viáveis".

O projeto Escola Permacultural é uma semente de inéditos viáveis, dispersada pelo Instituto Permacultura $\mathrm{Lab}^{1}$ como uma proposta pedagógica de EA escolar baseada na permacultura e na agroecologia como disciplinas a serem inseridas na grade curricular do ensino médio. O projeto é desenvolvido em duas escolas públicas da periferia da cidade do Rio de Janeiro. Desde 2018, o projeto ocorre no CIEP ${ }^{2}$ Raul Ryff, que se localiza no bairro de Paciência e em 2020 começou a ser desenvolvido no $\mathrm{CIE}^{3}$ Miécimo da Silva, localizado no bairro de Campo Grande.

O CIEP 312 Raul Ryff e o CIE Miécimo da Silva fazem parte da rede estadual de ensino, que é responsável pelo ensino médio. O Raul Ryff possui 940 estudantes e 42 professores, divididos em três turnos. Já o Miécimo da Silva possui 477 estudantes e 50 professores, divididos entre os turnos da manhã e da tarde, e, além do ensino médio regular, possui também o ensino médio técnico, com os cursos de edificações, administração e informática.

As disciplinas de permacultura e agroecologia foram agregadas ao currículo escolar a partir das disciplinas Estudos Orientados e Projeto de Vida. Suas inserções nas escolas se deram a partir do contato direto dos integrantes do instituto com as equipes de direção e de professores das escolas, não fazendo parte da rede estadual como um todo.
As duas disciplinas possuem carga horária de duas horas-aula semanais. A disciplina de permacultura é desenvolvida com duas turmas da $1^{\mathrm{a}}$ série do ensino médio tanto no Raul Ryff como no Miécimo da Silva, com cerca de 30 estudantes em cada turma. A disciplina de agroecologia ocorre como continuação à de permacultura, sendo desenvolvida com duas turmas da $2^{\text {a }}$ série do ensino médio no Raul Ryff, também com cerca de 30 estudantes em cada turma. No Miécimo da Silva, a disciplina de agroecologia ainda não foi iniciada.

Estudos Orientados e Projeto de Vida são disciplinas oferecidas para as turmas que fazem parte do programa Ensino Médio Inovador, que consiste em uma proposta do governo federal criada em 2009, com o objetivo de apoiar e fortalecer os sistemas de ensino estaduais no desenvolvimento de propostas curriculares inovadoras. Suas ações são incorporadas gradativamente ao currículo na busca da ampliação do tempo dos estudantes na escola e da diversidade de práticas pedagógicas.

As disciplinas Estudos Orientados e Projeto de Vida são flexíveis de acordo com as possibilidades pedagógicas de cada unidade escolar, e são pautadas na disponibilidade de professores, nos interesses dos estudantes e nas oportunidades de projetos externos, como o projeto Escola Permacultural. No CIEP Raul Ryff, as disciplinas de permacultura e de agroecologia foram ofertadas como optativas dentre outras disciplinas lecionadas por professores efetivos da escola, como dança, desenho, cinema, música e dança japonesa.

\footnotetext{
${ }^{1}$ Instituto Permacultura Lab é uma organização não governamental sem fins lucrativos, com sede na cidade do Rio de Janeiro, que atua nas áreas da agroecologia, da agricultura urbana, da educação ambiental e da permacultura.

${ }^{2}$ Centro Integrado de Educação Pública.

${ }^{3}$ Centro Interescolar Estadual.
} 
Por meio de uma proposta pedagógica que une teoria e prática de maneira interdisciplinar, as disciplinas de permacultura e de agroecologia estimulam a autonomia, a criatividade e o pensamento crítico dos estudantes, a partir de atividades que promovem reflexões sobre questões socioambientais presentes em seus cotidianos, nas escalas micro e macrossocial. Além disso, busca-se a construção coletiva de soluções que resultam em intervenções práticas no ambiente escolar, criando assim um laboratório vivo, que pode ser entendido como um ambiente de experimentação e desenvolvimento coletivo.

Durante o período de execução do projeto, as principais intervenções permanentes foram a criação de uma central de compostagem, que é utilizada para tratar os resíduos orgânicos produzidos na escola, e a implementação de um sistema agroflorestal em parte do pátio da escola. Os grandes temas abordados nas aulas foram: sistemas agroflorestais, compostagem, plantas medicinais e fitoterápicos, yoga e meditação, alimentação saudável, agricultura urbana, diversidade e comunidades tradicionais. A metodologia utilizada na abordagem dessas temáticas incluiu aulas expositivas, rodas de conversa, aulas teórico-práticas e aulas de campo.

\section{Método de pesquisa}

A pesquisa aqui apresentada foi realizada a partir da metodologia da Investigação-Ação-Participante (Fals Borda, 1999). Investigação-Ação-Participante consiste em uma modalidade de pesquisa qualitativa, que se orienta a partir da realidade social e cotidiana dos participantes e se embasa em alguns princípios, como: a superação da distinção entre pesquisador e objeto de pesquisa (grupo ou população a ser estudada), no sentido de valorizar os grupos que integram a pesquisa e os saberes que eles possuem; e a produção de conhecimento a partir da práxis, que consiste na interação entre teoria e prática, sob uma perspectiva de reflexão-ação, que promove uma interação entre conceitos e teorias com as realidades locais (Fals Borda, 2015).

Sob essa perspectiva, foram coletadas informações a partir de observações do cotidiano escolar. Com o objetivo de avaliar o desenvolvimento das disciplinas e o processo de ensino-aprendizagem, foram aplicados 3 questionários semiestruturados para todos os estudantes que integravam as turmas (no início, no meio e no fim do ano), e foram realizados encontros de avaliação da disciplina ao final de cada semestre, envolvendo professores e estudantes.

\section{Análise do projeto - dimensões pedagógicas da permacultura e da agroecologia}

\subsection{Educação ambiental, permacultura e agroecologia contextualizadas com o território}

O desenvolvimento do projeto Escola Permacultural se dá sob o desafio de acontecer na Zona Oeste da cidade do Rio de Janeiro, uma região originalmente rural, que passa por um processo degradante de urbanização e exclusão, marcado pela falta de acesso a serviços de saúde, cultura e educação, e pelo recebimento de indústrias poluidoras, como indústrias siderúrgicas e de produção de substâncias para o refino do petróleo (Tavares, 2019).

Nessa região, há um segundo problema que consiste na ausência de reconhecimento, por parte 
do poder público, dos agricultores familiares que ali residem há gerações, nos maciços, áreas florestais e seu entorno. Por essas razões, tais famílias de agricultores vivem sob constante ameaça das políticas preservacionistas e da especulação imobiliária.

As diferentes atividades desenvolvidas nas disciplinas são, sempre que possível, contextualizadas com as questões sociais locais. Algumas questões são levadas pelos professores, a partir de um estudo prévio do histórico da região e também pelas suas próprias experiências de vida, visto que parte da equipe pedagógica vive na mesma região das escolas. Outras questões são levadas pelos estudantes, tendo em vista que o projeto possui uma base pedagógica freireana, que proporciona que os estudantes participem ativamente.

O projeto conta com a colaboração do escritório modelo de arquitetura e urbanismo da Universidade Federal do Rio de Janeiro - Abricó, que é composto por estudantes e professores do curso de arquitetura e urbanismo, e é responsável por ministrar um módulo das disciplinas. Em 2018, a principal atividade desenvolvida com a turma de permacultura consistiu em um exercício para pensar a relação da escola com o bairro. Nele, os estudantes dividiram-se em grupos e cada grupo recebeu um mapa da escola e das ruas do entorno, impresso em tamanho A0 (119 x $84 \mathrm{~cm})$. A partir da observação do mapa, a discussão foi facilitada pela pergunta "O que vem à sua cabeça quando você pensa neste lugar?". Cada grupo fez anotações e debateu sobre como eles ocupam esse território ${ }^{4} \mathrm{e}$ o que os elementos ali presentes significam para a vida de cada um - ruas, praças, escola, rio, campo de futebol, local de depósito de lixo, entre outros.

No ano de 2019, foi realizada a mesma atividade do mapa com a nova turma de permacultura. Já com a turma de agroecologia $-2^{\mathrm{a}}$ série do ensino médio - foi pensado mais objetivamente o espaço da escola a partir de uma maquete. Nela, os estudantes debateram sobre como é a escola atualmente e como seria a escola ideal para eles.

Estudar sobre o espaço escolar e sobre o território é um importante exercício para que os estudantes pensem de maneira crítica e discutam sobre o local em que vivem e consigam identificar os pontos positivos presentes no seu cotidiano, bem como as contradições e situações de injustiça que enfrentam diariamente. Essa é uma das principais bases da perspectiva crítica da EA, que indica que as atividades do projeto sejam elaboradas de maneira contextualizada com a realidade local, e que haja participação ativa dos estudantes e integração com toda a comunidade escolar.

Outro ponto de comunicação direta do projeto com a realidade dos estudantes foi a participação do MC Estudante no ano de 2019, na abertura do festival cultural que ocorre anualmente na escola, o Eurekando. Ao longo de dois anos de projeto, pôde-se perceber que um forte elemento presente na realidade dos estudantes do CIEP Raul Ryff é o rap. Para além de um estilo musical, o rap para eles é uma forma de linguagem e de expressão. Muitos estudantes participam de rodas de rima e fazem parte de grupos de rap. O MC Estudante é conhecido por compor letras com assuntos de disciplinas como

\footnotetext{
${ }^{4}$ Entende-se território como o espaço geográfico somado às relações sociais que ali se manifestam, considerando suas dimensões políticas, econômicas e culturais (Raffestin, 1993).
} 
história, biologia, sociologia e até revisões para o ENEM, sempre com uma abordagem crítica sobre os temas, em forma de rap.

Uma das bases da permacultura e da agroecologia é a integração e valorização de múltiplos saberes. Ao possibilitar a apresentação do MC Estudante para toda a escola, o projeto promove uma "ecologia dos saberes" (Santos, 2018), onde saberes e elementos culturais de populações urbanas marginalizadas, como o hip-hop e o rap, são valorizados, estabelecendo assim um diálogo com o saber científico.

\subsection{Agrofloresta como elemento pedagógico}

Em abril de 2018, teve início a implementação de uma agrofloresta no pátio da escola. Agrofloresta, ou sistema agroflorestal, consiste em um modelo de plantio que tem como base o processo de sucessão ecológica. Com isso, busca-se, principalmente, um aumento gradativo da biodiversidade do agroecossistema e a melhora das condições do solo. Sendo assim, as agroflorestas são consideradas como um modelo de agricultura que associa produção de alimentos com recuperação ambiental (Londres $e t$ al., 2017).

A agrofloresta na escola serve como um elemento pedagógico que proporciona a abordagem de temas ligados a várias disciplinas. No caso do projeto Escola Permacultural, além de assuntos relacionados às disciplinas de biologia, geografia e história, a agrofloresta facilitou a abordagem de assuntos como segurança e soberania alimentar, políticas públicas, cidadania e economia solidária.

O início da atividade pedagógica da agrofloresta consistiu em um debate sobre alimentação e produção de alimentos, onde os estudantes falaram se já tiveram algum contato com a agricultura. Diversos estudantes relataram que seus familiares já praticaram a agricultura, seja para a comercialização ou para consumo próprio, mas a maioria não desenvolve mais essa atividade.

Em seguida, foram realizadas duas aulas sobre o histórico e o desenvolvimento da agricultura no mundo e o surgimento da agricultura industrial, abordando suas contradições e injustiças locais e globais, a partir de correlações com termos como: monocultura; sementes transgênicas; revolução verde; desertos alimentares; desmatamento; êxodo rural; fome no Brasil e no mundo; impactos dos agrotóxicos na saúde da população e ao meio ambiente. Posteriormente, foi realizada uma dinâmica onde, em grupos de cerca de cinco pessoas, os estudantes separaram palavras e fotos ligadas à agricultura convencional de palavras e fotos ligadas à agroecologia e realizaram um debate.

As aulas introdutórias consistiram em momentos de grande relevância no processo de desenvolvimento da disciplina. Nessas aulas foram apresentadas informações sobre os impactos da agricultura industrial e suas interlocuções com questões sociais, ambientais e econômicas. Além disso, os estudantes demonstraram interesse em aprender mais sobre agroecologia e agroflorestas, dando entusiasmo para o grupo avançar com os estudos.

As etapas seguintes consistiram no estudo sobre o solo, com análise do solo da escola; estudo sobre os princípios básicos da agrofloresta; e planejamento do plantio. Antes do plantio, os professores realizaram uma aula teórica sobre características gerais dos vegetais, como a fotossíntese, e sobre os princípios da agrofloresta, como a sucessão ecológica, as relações interespecíficas, o controle 
biológico de pragas e o manejo ecológico do solo. Em seguida, teve início o planejamento e desenho dos canteiros, onde os estudantes e os professores discutiram sobre quais espécies utilizar, o formato dos canteiros, a disposição dos canteiros no terreno em relação ao sol e o posicionamento das espécies dentro do canteiro. Nesse momento, os professores estimularam os alunos a observar as características físicas e biológicas do pátio da escola, como o trajeto do sol e a mudança na incidência solar no local do plantio de acordo com as horas do dia, a direção do vento, a presença de insetos e de outros animais no local e a existência de plantas indicadoras das características do solo.

Após a realização desses estudos, foram definidos os desenhos dos canteiros que os estudantes e professores consideraram como mais eficientes para o plantio. Em seguida, tiveram início as atividades de plantio, que foram realizadas ao longo de 3 aulas. Durante essas aulas, foram implementados cinco canteiros lineares, com dez metros de comprimento por um metro de largura e um canteiro em forma de espiral, onde foi seguida a sugestão de um grupo de estudantes por um formato experimental.

O manejo do plantio foi feito ao longo do ano, em aulas específicas e em mutirões marcados com os estudantes de maneira livre, quando era percebida a necessidade de determinada intervenção. A presença da agrofloresta na escola promoveu a reaproximação dos estudantes com elementos naturais e com a prática da agricultura, que muitos de seus familiares já tiveram, mas foi sendo perdida ao longo das gerações. Um aspecto interessante consistiu no fato de alguns estudantes comentarem com orgulho que seus familiares eram ou já tinham sido agricultores. Isso representa uma mudança de perspectiva da juventude em relação à agricultura, que em geral é vista com uma prática no mínimo desinteressante, quando não como motivo de vergonha.

No ano de 2019, o projeto começou a fazer parte do Sistema Participativo de Garantia (SPG), da Rede Carioca de Agricultura Urbana em conjunto com a Associação de Agricultores Biológicos do Estado do Rio de Janeiro (ABIO), com o objetivo de realizar a certificação orgânica do plantio realizado na escola. O SPG consiste em uma forma de avaliação da conformidade da produção orgânica, obtida por meio da verificação conjunta dos próprios agricultores e representantes de instituições de assessoria técnica, do cumprimento das normas gerais de certificação contidas na legislação. Há a realização de reuniões mensais entre o grupo, juntamente com a visita de avaliação da propriedade de algum agricultor. Esse formato promove uma aproximação entre os agricultores e, mais do que realizar a fiscalização da conformidade orgânica do plantio, cria-se uma rede de apoio, de troca de experiências e de informações. Ao optar pelo SPG, pretende-se estabelecer um sistema de garantia que não dependa diretamente de técnicos e auditores externos, onde os agricultores participantes da rede assumam um compromisso de controle social ativo na verificação do cumprimento das normas gerais de certificação (Caldas et al., 2012).

A participação da escola nesse processo permitiu que os estudantes percebessem a relevância e a aplicabilidade concreta do projeto que desenvolvem e do conteúdo estudado, o que faz com que estudar e frequentar a escola sejam processos atrativos. Além disso, se apresenta como uma possibilidade real para a superação dos desertos alimentares (Beaulac et al., 2009), por meio da utilização do espaço escolar para a produção e acesso da população a alimentos saudáveis. 
A partir de suas narrativas e dos questionários periódicos de avaliação, pode-se perceber como o desenvolvimento de temas contextualizados com a realidade dos estudantes estimulam o pensamento crítico e a capacidade de interpretação, de maneira complexa, das diversas questões vivenciadas no dia a dia. Dessa maneira, os estudantes tornam-se capazes de questionar suas condições de vida e de buscar outros caminhos, como cidadãos ativos na sociedade. As falas de uma estudante da turma de permacultura e uma da turma de agroecologia do ano de 2019, realizadas durante as rodas de conversa de avaliação da disciplina, apresentam bem essa ideia:
Eu acho que assim, desde criança a gente tem aquele negócio de mudar o mundo, né. E aqui a gente aprende um pouquinho por onde a gente pode começar a mudar o mundo. Eu acho que é isso que a permacultura faz, ensina a gente, dá o caminho de por onde a gente pode começar [...] (Estudante 1).

A disciplina nos estimula a pensar de forma filosófica e prática sobre a natureza, portanto, da espécie humana. Isso interfere diretamente nas minhas relações interpessoais e intrapessoais por criar uma rede de pensamentos filosóficos e agradáveis. E é claro, melhora fisicamente o ambiente com o que é aprendido (Estudante 2).

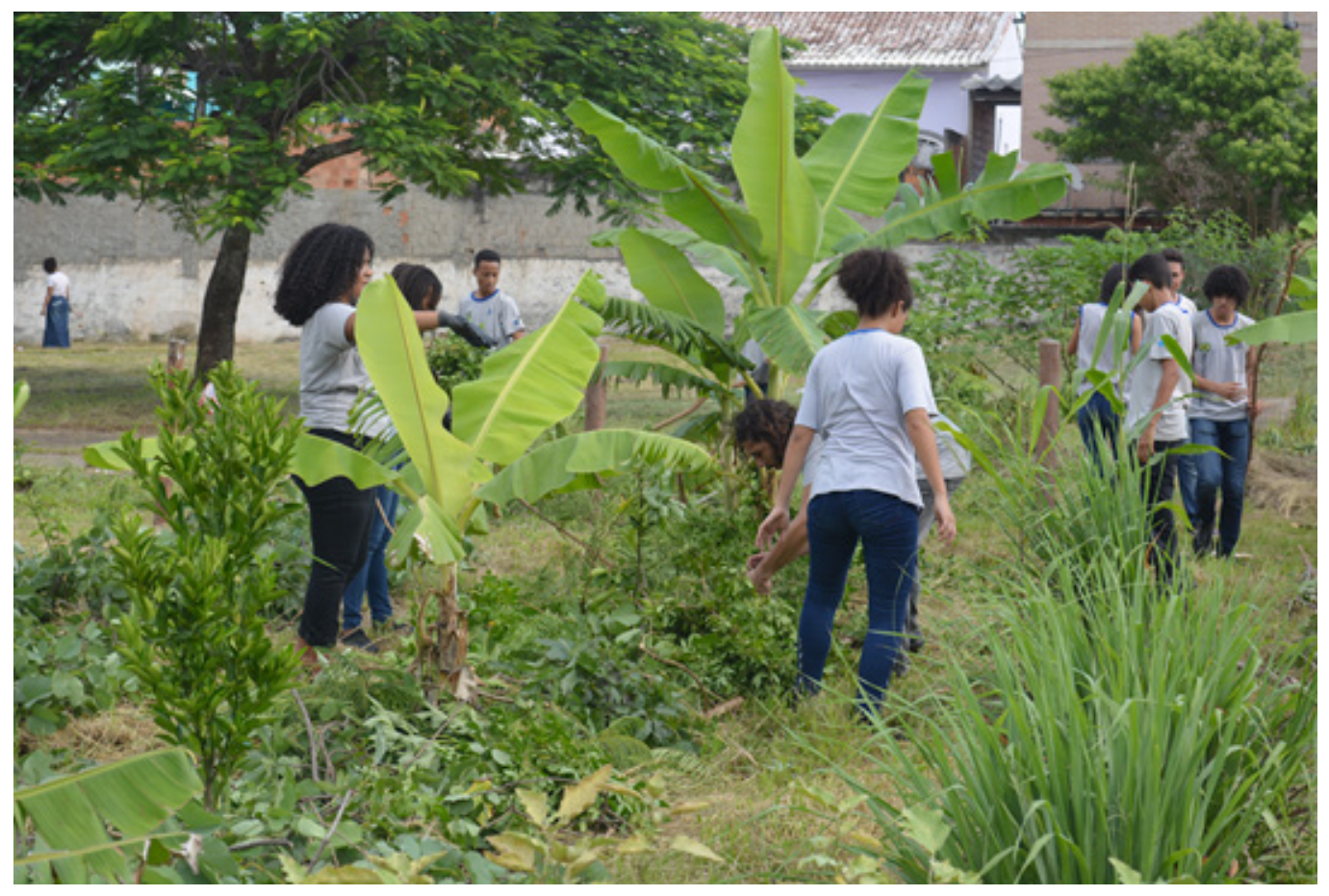

FIGURA 1 - Aula na agrofloresta em 2019.

FONTE: Acervo Instituto Permacultura Lab, 2019. 


\subsection{Sementes aladas: indo além da sala de aula e das disciplinas}

Por meio da consideração de múltiplos saberes e do uso das áreas externas da escola, a EA desenvolvida pelo projeto apresenta uma nova visão sobre o processo pedagógico, mostrando a possibilidade da extrapolação dos espaços fechados da sala de aula e dos estudantes atuarem ativamente no processo formativo. Essas características despertam transformações na instituição escolar, gerando mais estímulo aos estudantes e atraindo a atenção de outros professores e da direção. Isso pode ser percebido com as falas de duas estudantes, da turma de agroecologia e de permacultura, respectivamente:

A diferença é que aprendemos na parte física, que nos ajuda bastante a entender melhor, porque interagimos com a natureza e não com o papel e o lápis (Estudante 3).

Eu posso ter aulas ao ar livre e não fico copiando na sala de aula. Posso conhecer mais a natureza, sobre as plantações, sobre o meio ambiente e muito mais (Estudante 4).

Com o passar do tempo e conforme as intervenções na escola foram se tornando mais visíveis - com o crescimento da agrofloresta, a construção da central de compostagem e as aulas de yoga ao ar livre -, a disciplina começou a chamar mais atenção de diversos professores, que movidos pela curiosidade e possibilidade de integrar disciplinas do currículo com as práticas propostas pelas disciplinas de permacultura e de agroecologia, entraram em contato com a equipe pedagógica do projeto.
O primeiro contato veio a partir de uma professora de geografia que apresentou a proposta de trabalhar em conjunto com sua disciplina o tema de solos, a partir de práticas na agrofloresta. Outra importante aproximação foi com a professora de química, que demonstrou interesse pelo projeto em diversos momentos e acompanhou uma aula de campo realizada no maciço da Pedra Branca, para conhecer as atividades dos agricultores locais e participar da colheita do caqui. A partir dessa aproximação, iniciou-se uma articulação para pensar aulas em conjunto, como a ideia de uma aula de química sobre destilação de óleos essenciais, utilizando as plantas produzidas na agrofloresta como matéria-prima.

Outra participação significativa foi a de um professor de biologia, que desde o início do projeto se envolveu em diversas atividades, principalmente as envolvidas com plantio e manejo da agrofloresta, mesmo fora do seu horário de trabalho. Em 2019, ele foi transferido para uma escola em outro bairro, porém voltou para participar de um mutirão. Além disso, iniciou um projeto semelhante na sua nova escola, com o plantio de uma agrofloresta no pátio. Já no ano de 2020, o professor de educação física também entrou em contato procurando por orientações para dar início ao desenvolvimento de uma horta com alunos de uma escola municipal em que trabalha.

Entre os temas de grande destaque no projeto estão o yoga e a meditação. Eles fazem parte da grade curricular das duas disciplinas e são desenvolvidos por meio da colaboração com a professora de yoga e cientista ambiental, Tainá Antonio, idealizadora do projeto Yoga Marginal. Os estudantes aprendem na teoria e na prática sobre a filosofia do yoga e tem acesso aos benefícios físicos e mentais, 
que são apontados pelos próprios estudantes, como a redução da ansiedade e o desenvolvimento do autoconhecimento.

Esses resultados demonstram o potencial pedagógico das atividades relacionadas à agroecologia $\mathrm{e}$ à permacultura, que enriquecem o ambiente escolar, transformando-o em um ambiente estimulante e integrador. Percebe-se também que esses temas inspiram outros professores a replicar os fundamentos e estratégias pedagógicas abordados pelo projeto em diversos espaços de educação.

\subsection{Crescendo junto para florir}

A presença da agroecologia e da permacultura na escola, por meio de disciplinas desenvolvidas sob uma abordagem freireana, promovem a criação de espaços horizontais. O comprometimento com a horizontalidade na sala de aula proporciona a superação das hierarquias coercitivas, tão presentes nas escolas e universidades e com isso estimula a existência do diálogo. Desse modo, os estudantes são reconhecidos em suas particularidades e se reconhecem como integrantes da comunidade escolar de que fazem parte.

De acordo com Freire (2014), uma proposta pedagógica dialógica tem início no momento em que é definido o conteúdo programático da disciplina. Nesse contexto, o conteúdo programático dialógico não pode ser uma imposição, mas sim uma proposta, em que os professores atuam como mediadores dos estudantes em relação às bases teóricas e atividades pedagógicas.

No projeto Escola Permacultural, o conteúdo programático das disciplinas segue esses princípios dialógicos. Seu desenvolvimento é embasado em um planejamento anual feito previamente pelos professores, porém tal planejamento é aberto para os estudantes nos primeiros dias de aula e é revisitado por todos no início do segundo semestre. Além disso, o planejamento é flexível para sofrer alterações de acordo com o desenvolvimento das aulas e interesse dos estudantes. Dessa maneira, há um caráter democrático nas disciplinas, onde todos têm a possibilidade de participar ativamente da sua construção, garantindo sua base dialógica.

Um exemplo da construção coletiva da disciplina se deu no ano de 2019, onde em diversas aulas foram levantadas, pelos estudantes, questões sobre gênero, identidade, feminismo e sexualidade. Nesses momentos, foi observado pelos professores uma diversidade de opiniões, indo desde grande interesse e curiosidade por parte de alguns estudantes, que muitas vezes se identificavam com as pautas, até alguns comentários de cunho preconceituoso. Diante dessa realidade naturalmente polêmica, os professores convidaram o Coletivo Manas para realizar uma aula e mediar o debate sobre os temas. O coletivo, formado por mulheres, promove cine debates sobre pautas relacionadas a questões de gênero contextualizadas com diferentes perspectivas sociais.

$\mathrm{O}$ encontro realizado na escola contou com a presença de duas integrantes do coletivo que atuam na curadoria dos temas e facilitação do debate, e uma convidada, mulher travesti, negra e estudante de graduação em uma universidade federal. $\mathrm{O}$ mais enriquecedor, segundo a narrativa dos próprios estudantes, foi a presença da convidada, que a partir de sua história de vida suscitou um rico debate, quebrando diversos tabus e preconceitos para muitos estudantes. Foi possível perceber a relevância dessa aula para trazer à tona o debate sobre a importância 
da diversidade em suas múltiplas dimensões - biológica, social, cultural, étnica e religiosa.

O diálogo genuíno consiste em uma exigência existencial, onde o encontro de duas ou mais pessoas, permeadas por suas realidades de vida e suas situações cotidianas, promove a possibilidade de que todas expressem suas ideias e com isso haja acolhimento entre as reflexões e ações de cada uma (Freire, 2014). Esse processo tem como pressuposto básico a confiança, que não existe a priori, mas é construída com o tempo.

A construção da confiança com os estudantes é um processo que pôde ser percebido em todas as turmas. No início dos anos letivos, quando os estudantes ainda não conhecem os professores nem a proposta dialógica e emancipatória das disciplinas, costuma haver certa resistência à participação mais ativa nas aulas. Isso pode ser facilmente compreendido, visto que, em geral, as escolas possuem uma estrutura bastante verticalizada, onde os estudantes devem apresentar uma postura passiva frente aos professores.

Com o passar do tempo - em geral entre um e dois meses - os estudantes começam a se acostumar com a proposta da disciplina e começa a surgir também uma relação mútua de confiança dos estudantes entre si e com os professores. Com isso, a postura passiva dos estudantes vai deixando de existir. Nesse momento, a turma se transforma em uma "comunidade de aprendizagem", onde cada indivíduo reconhece que sua atuação é fundamental para o desenvolvimento do processo pedagógico (Hooks, 2017).

A existência da confiança nas comunidades de aprendizagem construídas com as disciplinas de permacultura e de agroecologia é amplamente percebida pela satisfação que os estudantes apresentam em participar das atividades propostas. Além disso, em diversos momentos durante os debates promovidos, vários estudantes já trouxeram à tona questões pessoais e sentimentos, que dificilmente seriam apresentados em outras turmas, e apontaram que o projeto promove um resgate das relações sociais, baseadas na cooperação e no acolhimento. A existência de relações construtivas e de confiança nas turmas pode ser observada nas falas de um estudante da turma de agroecologia e de um da turma de permacultura de 2019:

A liberdade de expressão, as interações, o retorno que tem as nossas reclamações, aqui também nós somos ouvidos, podemos tirar dúvidas mais facilmente e acima de tudo nós temos a liberdade de criar vínculo com os professores (Estudante 3).

A permacultura reforça muito um pensamento que eu tenho que é o seguinte: Tem muitas pessoas que falam em preservar florestas, preservar os animais, etc. Mas como você quer ajudar esse espaço se você não ajuda a sua própria espécie, que é o ser humano? Para você conseguir formar uma rede de humanos bons, que têm força de vontade, vitalidade para ir para floresta e aprender com ela, você tem que ter humanos com a saúde mental boa, para não se autodestruir e então proteger a floresta. [...] Essa aula, a permacultura inteira, pelo menos ao que eu vi, ela fala muito sobre humanidade. Vocês conseguiram criar dentro da gente uma humanidade muito positiva, por que na minha casa, eu não crio uma humanidade tão positiva assim, eu criei uma humanidade autodestrutiva, pesada. Mas aqui não, foi um ambiente mais acolhedor (Estudante 5). 


\subsection{Dificuldades do caminho}

Durante o desenvolvimento do projeto, várias dificuldades foram vivenciadas. Tais dificuldades vão desde particularidades das instituições escolares até questões estruturais do sistema educacional.

Como o projeto é realizado por uma organização não governamental - o Instituto Permacultura Lab -, um grande desafio foi a obtenção de recursos para financiar os gastos com a equipe pedagógica e com os materiais necessários para o desenvolvimento das aulas. $\mathrm{O}$ instituto conseguiu esses recursos através de fundações que apoiam projetos sociais. No ano de 2018, os recursos foram conseguidos através de um edital, e nos anos de 2019 e 2020 através de apoio direto.

Para que não haja a dependência de ONGs e instituições externas às escolas no desenvolvimento de projetos como este, é necessário que os professores que integram as redes públicas de ensino sintam-se seguros e capacitados para o desenvolvimento destes projetos. Para tal, se faz necessário que ocorra a formação continuada dos professores. Isso poderia ser solucionado com a promoção de cursos pelas secretarias de educação e com o estímulo e garantia de condições por parte das secretarias para que os professores realizem pós-graduação lato sensu e strictu sensu.

Visando contribuir com a ampliação do número de professores capacitados para o desenvolvimento de atividades de educação ambiental significativas, o Instituto Permacultura Lab e o Grupo de Estudos em Educação Ambiental desde el Sur - GEASur, da Universidade Federal do Estado do Rio de Janeiro, promoveram, em 2020, um curso para professores onde foram apresentadas as metodologias e reflexões sobre conceitos e temas desenvolvidas no projeto Escola Permacultural. O curso foi desenvolvido no formato on-line, com cerca de 16 horas de atividades, e contou com a participação de 137 pessoas de todo o Brasil, envolvendo professores da educação básica, estudantes de licenciatura, professores de nível superior e educadores em contexto não formal.

Um grande desafio vivenciado durante o desenvolvimento do projeto foi conseguir o envolvimento dos professores de outras disciplinas e dos funcionários da escola. Mesmo com as disciplinas presentes no projeto político pedagógico da escola e com a sua apresentação nos conselhos de classe e em momentos diversos durante o cotidiano escolar, poucos professores e demais funcionários se envolveram com as disciplinas. A dificuldade do envolvimento de professores em outras atividades nas escolas, além das aulas convencionais, foi discutida por Martins et al. (2019), que apontam que por trás de uma aparente falta de interesse, estão fatores como baixa remuneração, sobrecarga de trabalho, contratos temporários e terceirização.

Um outro fator, que não foi uma dificuldade nesta experiência, mas pode ser limitante em muitas escolas, é a disponibilidade de espaço externo para a realização do plantio e das atividades correlatas. Esse fator pode ser superado com o uso de vasos de diferentes tamanhos e de caixotes de madeira para o plantio.

\section{Considerações finais}

Esse projeto possibilitou perceber que a inserção das temáticas da agroecologia e da permacultura como disciplinas escolares, atreladas às bases da 
educação popular, possibilitam que a EA, em uma abordagem crítica, seja trabalhada como um campo que propicia a reflexão da realidade social em sua complexidade, ao mesmo tempo em que permitiu elaborar processos de desenvolvimento da autonomia dos estudantes, numa ação que constituiu a promoção de conexões temáticas interdisciplinares a partir da realidade escolar.

O desenvolvimento das disciplinas, embasado em referenciais da agroecologia, da permacultura, da educação ambiental crítica e da educação popular, estimulou a criação de um solo fértil, propício para o desabrochar de processos criativos a partir de temas variados pertencentes ao cotidiano dos alunos, indo dos processos bioquímicos da fotossíntese ao rap. Dessa maneira, os estudantes exploram as atividades escolares a partir de seus próprios universos, valorizando-os para repensar a própria escola e o sentido da educação.

Esse processo de desenvolvimento do conhecimento mostrou que a agroecologia e a permacultura apresentam entrelaçamentos que possibilitam a visualização da realidade complexa e crítica do meio ambiente. Além disso, forneceram a dimensão prática que é fundamental que faça parte da EA em sua perspectiva crítica.

A EA crítica não pode se limitar ao desenvolvimento teórico e ao discurso crítico sobre a realidade. A permacultura e a agroecologia possibilitaram que a concretização dessa prática se materializasse numa dinâmica nutrida pela horizontalidade e por processos participativos. Iniciativas e temas que partiram dos estudantes foram incorporados às propostas do projeto, contribuindo para a criação de um ambiente acolhedor, com relações de confiança, que permitiram a expressão do potencial criativo dos estudantes e levaram ao exercício da práxis pedagógica, num processo leve e contínuo.

Essa experiência se mostrou um trabalho coletivo onde educação, participação social e articulação com a comunidade se entrelaçam. A diversidade de seres, corpos, ideias e atravessamentos foram fáceis de observar com as materializações dos processos que ensaiamos. Como destaque, tem-se a possibilidade de a escola cumprir um dos seus grandes papéis, que é o de contribuir para a construção de inéditos viáveis e catalisar a transformação efetiva da sociedade, por meio de processos pedagógicos humanizados, que criam elementos para sua realização de forma solidária, criativa e potente.

\section{Referências}

Acselrad, H. Ambientalização das lutas sociais - o caso do movimento por justiça ambiental. Estudos Avançados, 24(68), 103-119, 2010. doi: 10.1590/S010340142010000100010

Allen, M. R.; O. P. Dube; W. Solecki; F. Aragón-Durand; W. Cramer; S. Humphreys; M. Kainuma; J. Kala; N. Mahowald; Y. Mulugetta; R. Perez; M.Wairiu; K. Zickfeld. Framing and Context. In: Masson-Delmotte, V.; Zhai, P.; Pörtner, H.-O.; Roberts, D.; Skea, J.; Shukla, P. R.; Pirani, A.; Moufouma-Okia, W.; Péan, C.; Pidcock, R.; Connors, S.; Matthews, J. B. R.; Chen, Y.; Zhou, X.; Gomis, M. I.; Lonnoy, E.; Maycock, T.; Tignor, M.; Waterfield, T. (Eds.). Global Warming of $1.5^{\circ} \mathrm{C}$. An IPCC Special Report on the impacts of global warming of $1.5^{\circ} \mathrm{C}$ above pre-industrial levels and related global greenhouse gas emission pathways, in the context of strengthening the global response to the threat of climate change, sustainable development, and efforts to eradicate poverty. In Press, 2018. Disponível em: <https://www.ipcc.ch/sr15/>. Acesso em: 05/02/2021.

Almeida, M. W. B. Direitos à florestas e ambientalismo: seringueiros e suas lutas. Revista Brasileira de Ciências Sociais, 19(55), 33-52, 2004. doi: 10.1590/S0102- 


\section{3}

Altieri, M. Agroecologia: bases científicas para uma agricultura sustentável. São Paulo, Rio de Janeiro: Expressão Popular, AS-PTA, 3. ed., 2012.

Beaulac, J.; Kristjansson, E.; Cummins, S. A systematic review of food deserts, 1966-2007, Preventing Chronic Disease, 6(3), 1-10, 2009. Disponível em: https://www. ncbi.nlm.nih.gov/pmc/articles/PMC2722409/

Brasil. Lei $n^{\circ}$ 9795, de 27 de abril de 1999. Institui a Política Nacional de Educação Ambiental. Brasília: DOU de 28/04/1999.

Caldas, N. V.; Anjos, F. C.; Bezerra, A. J. A.; Criado, E. A. Certificação de produtos orgânicos: obstáculos à implantação de um sistema participativo de garantia na Andaluzia, Espanha. Revista de Economia e Sociologia Rural, 50(3), 455-472, 2012. doi: 10.1590/S0103-20032012000300004

Fals Borda, O. Orígenes universales y retos actuales de la IAP. Análisis Político, 38, 73-90, 1999. Disponível em: https://revistas.unal.edu.co/index.php/anpol/article/ view/79283

Fals Borda, O. Cómo investigar la realidad para transformarla. In: Fals Borda, O. Una sociología sentipensante para América Latina. Antología y presentación. México, D. F.: Siglo XXI Editores; Buenos Aires: CLACSO, 2015.

Floriani, N.; Floriani, D. Saber Ambiental Complexo: aportes cognitivos ao pensamento agroecológico. Revista Brasileira de Agroecologia, 5(1), 3-23, 2010. Disponível em: http://revistas.aba-agroecologia.org.br/index.php/rbagroecologia/article/view/9529

Freire, P. Pedagogia do Oprimido. Rio de Janeiro: Paz e Terra, 56. ed., 2014.

Guimarães, M. Educação Ambiental Crítica. In: Layrargues, P. P. (Org.). Identidades da educação ambiental brasileira. Brasília (DF): Edições Ministério do Meio Ambiente, 2004.

Guimarães, M. Por uma educação ambiental crítica na sociedade atual. Revista Margens Interdisciplinar, 7(9), 11-22, 2016. doi: 10.18542/rmi.v7i9.2767

Holt-Giménez, E.; Altieri, M. Agroecology, food sovereignty, and the new green revolution. Agroecology and
Sustainable Food Systems, 37(1), 90-102, 2013. doi: 10.1080/10440046.2012.716388

Hooks, B. Ensinando a transgredir: a educação como prática de liberdade. São Paulo: Editora WMF Martins Fontes, 2. ed., 2017.

Layrargues, P. P. A dimensão freireana na educação ambiental. In: Loureiro, C. F. B; Torres, J. R. (Orgs.). Educação ambiental: dialogando com Paulo Freire. São Paulo: Cortez, p. 7-12, 2014.

Layrargues, P. P.; Lima, G. F. C. As macrotendências político-pedagógicas da educação ambiental brasileira. Ambiente \& Sociedade, 17(1), 23-40, 2014. Disponível em: http:// www.scielo.br/pdf/asoc/v17n1/v17n1a03.pdf

Leff, E. Agroecologia e saber ambiental. Agroecologia e Desenvolvimento Rural Sustentável, 3(1), 36-51, 2002. Disponível em: http://taquari.emater.tche.br/docs/agroeco/ revista/ano3_n1/revista_agroecologia_ano3_num1_parte08_artigo.pdf

Londres, F.; Petersen, P.; Martins, G. Olhares agroecológicos: análise econômico-ecológica de agroecossistemas em sete territórios brasileiros. Rio de Janeiro: AS-PTA, 1. ed., 2017.

Martins, P.; Silva A. C.; Maneschy, D. M.; Sánchez, C.; Ambivero, M. C.; Lopes, A. F. Educação ambiental crítica, da teoria à prática escolar: análise da experiência de um projeto no contexto de uma escola pública do Rio de Janeiro. Revista Brasileira De Educação Ambiental, 14(2), 86-102, 2019. doi: 10.34024/revbea.2019.v14.2683

Monteiro, D.; Londres, F. Pra que a vida nos dê flor e frutos: notas sobre a trajetória do movimento agroecológico no brasil. In: Sambuichi, R. H. R.; Moura, I. F.; Mattos, L. M.; Ávila, M. L.; Spínola, P. A. C.; Silva, A. P. M. (Orgs.). A politica nacional de agroecologia e produção orgânica no Brasil: uma trajetória de luta pelo desenvolvimento rural sustentável. Brasília: Ipea, 53-83, 2017. Disponível em: http://repositorio.ipea.gov.br/bitstream/11058/8805/1/ Pra\%20que\%20a\%20vida.pdf

Nanni, A. S.; Blankensteyn, A.; Sigolo R. P.; Nór, S.; Venturi, M. Construindo a permacultura na academia brasileira. Revista Brasileira de Agroecologia, 13(1), 193-205, 2018. Disponível em: http://revistas.aba-agroecologia.org.br/ 
index.php/rbagroecologia/article/view/22439

Nolan, R. H.; Boer, M. M.; Collins, L.; Dios, V. R.; Clarke, J. M.; Kenny, B.; Bradstock, R. A. Causes and consequences of eastern Australia's 2019-20 season of mega-fires. Global Change Biology, 26, 1039-1041, 2020. doi: 10.1111/ gcb. 14987

Prates Júnior, P.; Custódio, A. M.; Gomes, T. O. Agroecologia: reflexões teóricas e epistemológicas. Revista Brasileira de Agroecologia, 11(3), 246-258, 2016. Disponível em: http://revistas.aba-agroecologia.org.br/index.php/rbagroecologia/article/view/16783/12310

Raffestin, C. Por uma geografia do poder. São Paulo: Editora Ática, 1993.

Santos, B. S. Na oficina do sociólogo artesão: aulas 20112016. São Paulo: Cortez, 2018.

Sevilla-Guzmán, E. Uma estratégia de sustentabilidade a partir da agroecologia. Agroecologia e Desenvolvimento Rural Sustentável, 2(1), 35-45, 2001. Disponível em: http://www.emater.tche.br/site/sistemas/administracao/ tmp/984142538.pdf
Tavares, T. R. R. Examinando a injustiça ambiental a partir da contaminação do ar e de inundações nos arredores da Companhia Siderúrgica do Atlântico/Ternium nos arredores da Baía de Sepetiba. AMBIENTES, 1(2), 211-251, 2019. doi: 10.48075/amb.v1i2.23780

Trajber, R.; Mendonça, P. (Orgs.). Educação na diversidade: o que fazem as escolas que dizem que fazem educação ambiental. Brasília: Secretaria de Educação Continuada, Alfabetização e Diversidade, 2007.

Trein, E. S. A Educação Ambiental Crítica: crítica de que? Revista Contemporânea de Educação, 7(14), 295-308, 2012. doi: 10.1590/S0103-20032012000300004

Veiga A.; Amorim, E.; Blanco, M. Um retrato da presença da educação ambiental no ensino fundamental brasileiro: o percurso de um processo acelerado de expansão. Brasília: Instituto Nacional de Estudos e Pesquisas Educacionais Anísio Teixeira, 2005. 